
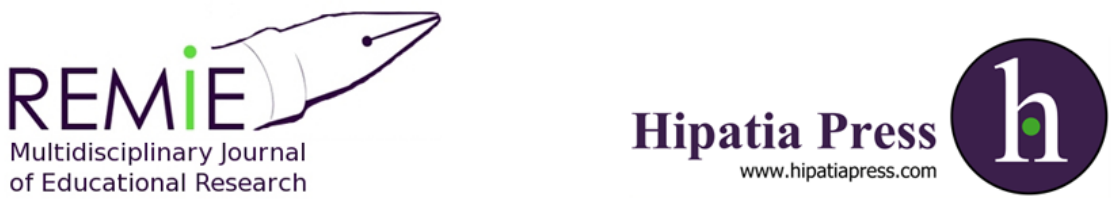

Instructions for authors, subscriptions and further details:

http://remie.hipatiapress.com

\title{
"Inside the head and out in the world". An approach to deep teaching and learning
}

Moisés Esteban-Guitart1, James Paul Gee2

1) University of Girona

2) Arizona State University

Date of publication: February 15th, 2020

Edition period: October 2019-February 2020

To cite this article: Esteban-Guitart, M. \& Gee, J. P. (2020). "Inside the head and out in the world". An approach to deep teaching and learning. Multidisciplinary Journal of Educational Research, Vol(10), 1-25. doi: 10.4471/remie.2020.4868

To link this article: http://dx.doi.org/10.447/remie.2020.4868

\section{PLEASE SCROLL DOWN FOR ARTICLE}

The terms and conditions of use are related to the Open Journal System and to Creative Commons Attribution License (CC-BY). 


\section{"Inside the Head and Out in the World". An Approach to Deep Teaching and Learning}

Moisés Esteban-Guitart

University of Girona
James Paul Gee

Arizona State University

(Received: 10 November 2019; Accepted: 6 Gener 2020; Published: 15 February 2020)

\section{Abstract}

In this theoretical paper, we will argue that to understand deep learning we need to accept that such learning is profoundly tied to teaching and that it takes places in situated and distributed affinity spaces, being both teaching and learning socio-mental processes. We shall outline what, in our view, are the key elements of deep learning. We will also describe a theoretical approach called the "Deep Teaching and Learning Model" (DTML). How this model is developed and sustained remains a central question for future research in educational research, and we conclude by identifying some of the challenges faced by formal schooling arising from the new, modern affinity spaces that we believe now make up the present-day geography of deep learning.

Keywords: deep learning, affinity spaces, appreciative systems, distributed teaching and learning 


\section{"Dentro de la Cabeza y Fuera en el Mundo". Una \\ Aproximación a la Enseñanza y Aprendizaje Profundo}

Moisés Esteban-Guitart

University of Girona
James Paul Gee

Arizona State University

(Recibido: 10 Noviembre 2020; Aceptado: 6 Enero 2020; Publicado: 15 Febrero 2020)

\section{Resumen}

En este artículo teórico sostenemos que para comprender el aprendizaje profundo es necesario aceptar la premisa bajo la cual dicho aprendizaje está vinculado a procesos de enseñanza situados y distribuidos en espacios de afinidad, considerándose los procesos de enseñanza-aprendizaje a la vez sociales y mentales. Describimos lo que nos parecen los elementos clave del aprendizaje profundo en el marco del modelo teórico que llamamos aquí "Enseñanza y Aprendizaje Profundo" (EAP). La forma en que este modelo se desarrolle y se mantenga se convierte en una cuestión central para la investigación futura en investigación educativa. Concluimos identificando algunos desafíos que la escolarización formal afronta en los nuevos espacios de afinidad que son la geografía contemporánea del aprendizaje profundo.

Palabras clave: aprendizaje profundo, espacios de afinidad, sistemas apreciativos, enseñanza y aprendizaje distribuido 
ver the last two decades, a great deal of work in the learning sciences and in neuroscience has given rise to new perspectives as to what exactly constitutes deep learning (Bransford, Brown, \& Cocking, 2000; Gee \& Esteban-Guitart, 2019; Marblestone, Wayne, \& Kording, 2016). At the same time, studies in the field of Digital media and learning have argued that many out-of-school learning sites reflect these new perspectives of deep learning better than many of today's schools (Gee, 2017; Ito, Gutiérrez, Livingstone, Penuel et al., 2013; Jenkins, Ito, \& Boyd, 2016). Consequently, a prominent issue now is how schools could better engage in deep learning and, indeed, what they can learn from out-of-school learning sites (Barron \& Bell, 2015; Esteban-Guitart, 2016; Gee, 2007; Jenkins, 2009; Lee, 2017; Vadeboncoeur, Kady-Rachid, \& Moghtader, 2014).

One thing that has largely been absent in all of this work on deep learning is the role of teaching. We would argue, however, that the emerging views of deep learning imply that such learning is profoundly tied to teaching and that this enables us to reintegrate teaching with learning (Subero, Llopart, Siqués, \& Esteban-Guitart, 2018).

When behaviorism was ascendant in psychology, the ideas of learning and teaching were bound tightly together. Learning was a behavioral response to a pattern of real-world stimuli. Teaching was any force that regimented such stimuli to create those responses. Learning could not take place without teaching, whether it be by humans or environmental structures - which were themselves often designed by humans (Skinner, 1954). Just as the stimulusresponse pair was an inseparable unit, so, too, was the teaching-learning unit. Furthermore, both were visible and out in the world. Behaviorists famously eschewed anything "internal" to the mind.

Behaviorism, in education at least, came to a dead end of course. This was because the theory ignored the highly complex processing carried out in human brains (and those of many other animal brains). Furthermore, behaviorism does not explain the specifically-human learning processes that are based on socio-mental processes of shared intentionality and cooperative reciprocity (Lázaro \& Esteban-Guitart, 2014; Tomasello, 2014). Humans seem to be the only species capable of regulating their behavior by conforming to cultural norms such as those in moral codes, rituals or video games (Tomasello, 2019). These are arbitrary and conventional practices that 


\section{Esteban-Guitart \& Gee-Deep Teaching and Learning}

require collective agreement, and which also involve a teaching-learning process to familiarize participants with the arbitrariness and conventionality that underlie such practices. People do not learn only through associations of stimuli and responses (a universal mechanism of learning but one that leads to superficial, although evolutionarily important, learning, such as 'learning' that 'fire burns'); we also learn by conforming to the normative expectations of others, which allows us to affiliate with them, as well by identifying with a particular cultural group (Tomasello, 2016). Institutions involve not simply conventions, traditions, rituals or customs but also a "deontology of futurebinding rights, responsibilities, duties, and obligations" (Packer \& Cole, 2019 , p. 175). In this sense, cultural groups offer normative guidelines for behavior and ways of seeing and interpreting the world (which we call 'frameworks') and this requires teaching processes that are unique to our species (Gee, 2017; Lázaro \& Esteban-Guitart, 2014).

Behaviorism was replaced by cognitive psychology which focused on the mind/brain as a computational device, much like the computer technology which, at that time, was beginning to infiltrate all walks of life. Learning was now something that happened deep inside the privacy of the mind, no longer a mere response to stimuli and instruction. Teaching, however, remained out in the real world (Elman, 1993).

Because the mind/brain was now seen as a computer, teaching became about transmitting rules, generalizations, and calculations that the mind/brain computer could use to process data into information in different knowledge domains. Teaching, in a sense, supplied "programs" ("software", "rules", "procedures") for the mind/brain computer to carry out. But cognitivism eventually ran into its own troubles. First, the human mind/brain does not actually work much like a digital computer. Digital computers are good at math and computing but they are not conscious and has not culture. In a few words, "computers models of the mind are invalid" (Tallis \& Aleksander, 2008, p. 55).

Digital technologies often outperform humans in certain areas but are far behind in others. Furthermore, when humans are taught rules and generalizations, they can often be adept at repeating them in tests, but they are not thereby necessarily any good at using them in context to solve problems (Lucas, Gratch, King, \& Morency, 2014). Second, decades of 
research have now demonstrated that the human brain is full of "brain bugs" - like "confirmation bias", "anchoring", and the "sunk cost fallacy" - and most often operates on unconscious "automatic pilot," based on affect and past experience, rather than on conscious and rational principles that require significant mental effort and are prone to failure (Buonomano, 2011). Finally, from the cognitive perspective, learning was reduced to individual cognitive processes that connected new knowledge with previously-acquired ideas, knowledge or images, which Ausubel (1963) referred to as meaningful learning. In our opinion, meaningful learning cannot be considered to be deep learning given that it undervalues the holistic nature of teaching and learning situations that are mediated not only by purely intellectual aspects of linking knowledge, but are also guided by meaningful activities within processes of affectivity, interest and passion. In other words, people learn basically through experiences that include sensations, cognitions, emotions, attentional processes, as well as processes of appreciation and assessment.

In this sense, we understand that during the experience of deep learning, the learners perform some kind of action in order to take in the experience, they care emotionally about the outcome of the action, and something or someone (any individual or group of individuals) is helping the learner to orient their attention. Action, caring and well-managed attention are the components of the processes we refer to here as deep teaching and learning. Learning is deep when it is holistic, when it involves not only processes of knowledge (knowing), but also of affectivity, interest, passion and evaluation/ appreciation (evaluating), of action (doing) and of identification (being). This occurs, for example, when a person learning about art, let's say, moves among various spaces, both virtual and real (which we will later define as distributed affinity spaces of teaching and learning) guided by a particular interest or passion, and constructs knowledge in relation to art, in general, or a specific artist, in particular. This person may take this action on a web page, in a museum or with a group of friends, and they might identify with a particular artistic discipline, a specific style or painter, which they value and appreciate. This would be an example of the deep learning processes which include all of the elements shown in Figure 1. 
6 Esteban-Guitart \& Gee-Deep Teaching and Learning

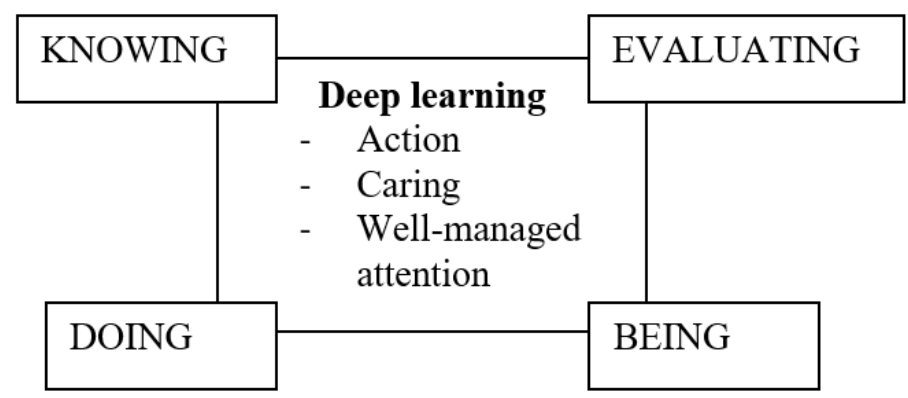

Figure 1. Elements of deep learning

\section{Development: A New Approach to Both Teaching and Learning as Socio-Mental Phenomena}

Over the years, cognitivism has been gradually replaced by a set of partially related viewpoints that go by names like "embodied cognition," "situated cognition," "distributed cognition," "evolutionary cognitive neuroscience", "prospective psych", and even "cognition in the wild." Moreover, a broad range of work in anthropology, sociology, linguistics, and evolution has now come to influence how we think about and study the mind/brain (Lee, 2017).

As we have said, a new approach to the mind/brain is emerging. The approach has yet to be given a commonly-agreed name and a single, consensus-backed formulation. We will offer one formulation here and call it the "Deep Teaching and Learning Model" (DTLM). Below, there is a schematic diagram of the key components of this formulation:

Based on mounting evidence from a variety of fields, we shall now outline how the theory of DTLM works. The numbers below refer to the numbers in Figure 2 above.

\section{Experience in LTM (1)}

Humans learn from experiences they have in the real world and via various media (the mind/brain treats real-world and media experiences similarly in many ways). Humans store the experiences they have in long-term memory (LTM) which, in the human brain, is nearly limitless. Hence, human learning 
begins with concrete experiences - not with abstractions, generalizations, or texts outside of experience (Kolb, 2015). For example, a passion for a certain artist might begin during a visit to an art gallery with the discovery of a painting that generates a specific artistic appreciation. Let's say the painting depicts a woman surrounded by stones, seaweed and water in what appears to be a beach or river mouth. What stands out here is that a noteworthy moment of the experience becomes a starting point for learning and that the interest it generates is often based more on ignorance, uncertainty or incomprehension, rather than on previous knowledge. The uncertain and precarious aspects of an experience lead to an effort to change what is given; in this sense, there is a projective dimension to the experience as the person tries to go beyond the present situation. Learning appears here as a more or less intentional process aimed at transforming the state of indetermination, of doubt, of uncertainty with regard to the person's understanding of the situation. That is, a situation of uncertainty poses a problem - the aesthetic appreciation of a work of art - and this constitutes the first moment of knowledge or learning.

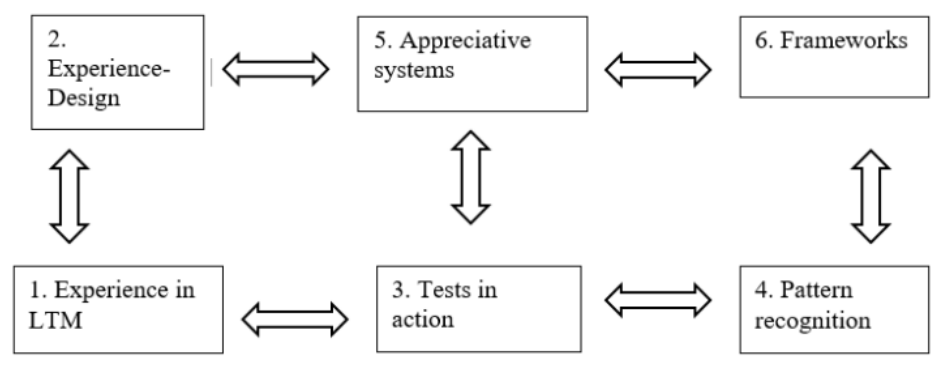

Figure 2. Key components of the Deep Teaching and Learning Model (DTML)

\section{Experience design (2)}

For "newbies" to any area (whether children or adults), experiences are often far too rich in details to be good for learning. Too much is going on at the 


\section{Esteban-Guitart \& Gee-Deep Teaching and Learning}

same time. For truly effective learning some force (we will name this force below) must curate or design the learner's learning experience in such a way that learning can work well (Gee \& Esteban-Guitart, 2019). This design process involves the following elements: a) the learner should have a goalbased action he/she wants to carry out; b) the learner must care affectively (emotionally) about the outcome of the action; c) the learner must be helped to manage his/her attention during the experience and to know what elements are most important to pay attention to; the learner must also know where and how to focus his/her attention; d) The learner must get feedback on whether and how the outcomes of his/her attempts to accomplish the action are good, bad, or indifferent for eventual success at accomplishing his/her goal and he/she must also get help with knowing what to try next if an action has not worked out. In the example concerning the painting, imagine that the curator of the exhibition says that the painting in question is an example of a typical trait of this particular artist: mixing a realistic figure with abstract techniques. The curator also points out details of the work that characterize the painting. From this point on, our learner looks online for other works by the artist and decides to improve and expand his/her knowledge of this particular style that combines realistic techniques (figurative art) with abstract techniques. In this situation, the learner has a 'problem' which needs solving: to understand a work of art that has caused a pleasing emotional impact of admiration. The curator of the exhibition acts as a force orienting the action of the learner.

\section{Experience in LTM and design (1 \& 2)}

Because of this 'designing force', that can be promoted by a cultural artefact, an individual or a group of people, discussed above, experiences stored in LTM are not "raw data", but edited and annotated in terms of what is relevant and in terms of elements in the experience that are foregrounded and ones that are backgrounded in terms of importance. This "editing" is a joint accomplishment of the learner and the force that designed the experience. The aesthetic experience that we are describing is engendered by the observers, the work of art produced by the painter (the artifact) and also by the curator who designed and subsequently explains the details of the exhibition. There is an "irreducible tension" (Wertsch, 1997) between the individual and the environment which is socially and culturally mediated; the 
aesthetic experience is the result of the negotiation between the individual and the artifacts and other social agents that accompany them - in this case, the picture, the audience and the curator.

There is growing evidence that the experiences stored in LTM are primarily future oriented and not past oriented (even though we call them "memories") (Klein, Robertson, \& Delton, 2010). The experiences (and their bits and pieces) in LTM are used as materials for mental simulations (imaginings) that allow humans to plan and prepare for future action. Because the "memories" stored in LTM are modified every time we use them, they become an unreliable record of the past. As we said earlier, each experience also supposes an effort to solve a question, a concern or uncertainty. It therefore has a projective dimension. The learner will find it hard to see another picture by the same artist in the same way, once she has heard or read the curator's explanation, and after what she has read and learned from the web.

\section{Tests in action and in mind \& Pattern recognition ( $3 \& 4)$}

Human knowledge does not start as general. It becomes general slowly across time. The human brain has a storage facility for experience (long-term memory) and several modules devoted to pattern recognition (a human superpower that can easily go awry) (Sekeres, Wincour, \& Moscovitch, 2018). Humans find patterns (general beliefs or knowledge) in their experiences across time only when they get repeated examples of the pattern (in their experiences in the world, via media, and via simulations in their minds) and can test how well these examples fit the hypothesized pattern. In our example, when contrasting different works of the painter, the learner observes that in all of them there is a similar pattern: the mixture of hyperrealistic techniques with almost photographic detail that are standard in figurative art, along with the use of abstract techniques, such as paint stains

and oils mixed with other materials to give texture and shape to the landscapes.

\section{Appreciative systems (5)}

The human mind/brain is full of "brain bugs" (Delgado, 2012). These include things like confirmation bias (the strong tendency to look for, pay attention 


\section{Esteban-Guitart \& Gee - Deep Teaching and Learning}

to, and favor only evidence that conforms what we already believe); the availability heuristic (making judgments based on recent events or information that can be easily recalled); the gambler's fallacy (believing that past random events can affect future events); and herd mentality (when the desire to be part of a group outweighs other and better considerations about how to feel or what to decide), and many more (Buonomano, 2011). Humans are quite prone to "finding" patterns that are spurious. Some force (also named below) must provide newbies with good ways to test hypothesized patterns in their ongoing experiences and simulations, and to evaluate or assess the outcomes of these tests. This is to say that some force must provide what we will call an appreciative system (Gee, 2017) and it must allow newbies to develop it further. An appreciative system is an evaluation or assessment system in a given knowledge domain that helps newbies know how to test and assess the judgments about the outcome of actions and tests of hypothesized patterns they make during and about their experiences. The curator himself, as well as the material found online and art reviews act as assessors (experts), verifying analytically the movement of the artist between realism and abstraction.

An important part of the appreciative systems newbies pick up is learning how to feel. Affect (emotion) leads people to make certain choices and not others, because these choices are emotionally charged as "good" (in terms of how they will feel in the future). Without such emotional charge, humans cannot act, decide, or think coherently. When nothing matters more than anything else, then nothing matters. When, how, and where to feel the sorts of emotions that direct good choices, decisions, and thinking is a product of the force that gives newbies appreciative systems.

Because of human brain bugs and because the vast majority of what goes on in the human mind and body - things that deeply determine how we feel, think, believe, and act - are unconscious and not open to conscious inspection, a great deal of human thinking and deciding needs to be supported by or, in some cases, even off-loaded to, good tools, collaborations with others, and human-engineered environmental structures and designs. Humans are "plug-and-play" devices that only work well when plugged into diverse people, smart tools, and well-designed environments. Left to their own devices, humans can be dangerous to themselves and to others 
(including narrow academic "experts" who tend to trust too much in what they know and not enough in what they don't know or in what other people in other domains know).

\section{Frameworks (6)}

Humans are prone to finding false or misleading patterns and to run with them without really testing them (Reber, 1989). So, social groups guide learners with regard to what count as important and useful patterns and subpatterns in experience, how these translate into general principles, and how to use them in future action and talk (Packer, \& Cole, 2019; Tomasello, 1999). All this help is a double-edged sword. On the one hand, it gives us meaning-making frameworks (perspectives, theories, viewpoints) which guide our thinking and acting. We all have different "takes" (or ideas) on such things as parenting, children, cooking, citizenship, art, morals, gender and sexuality, race, class, friendship, drinking, drugs, marriage, schooling, books, media, play and work, intelligence, strangers, politeness, animals, conservation, the environment, God, and anything and everything else, based on our socialization as learners within social groups.

These differing frameworks can lead to divisive interactions among humans. Since our frameworks come from enculturation and socialization we are often not fully consciously aware of them. We have not usually thought much about them in any very critical way. Nonetheless, because they have come from our own experiences and from social groups to whom we may be deeply attached, we often cherish our frameworks as part and parcel of who we are and what we stand for.

Whether the differing frameworks held by people in a given society - and now across our deeply connected global world - end up leading to respectful discussions or head-on conflict depends on the state of the society in which a person lives. Difference can be a source of strength and collective intelligence or a source of conflict, hatred, and even war. It is a key job of teaching to teach people how to gain meta-knowledge about frameworks and how to reflectively discuss differing frameworks. The goal is not to "convert" people to our own frameworks, but for each of us to better understand our own frameworks and those of others. The goal is also for people to gradually over time transform their frameworks, if they choose, and to come, in some 


\section{Esteban-Guitart \& Gee-Deep Teaching and Learning}

instances, to converge enough with others in the service of peace and collaborative problem solving.

\section{Teaching and Deep Learning}

We have talked about two unnamed forces in the above outline of deep leaning. The first is a force that designs experiences to make them good for learning. The second is a force that give learners appreciative systems in different domains, that is, judgment, assessment, evaluation criteria for what is a good result when acting (given a specific goal) and what are good ways to test hypothesized patterns in experience (generalizations), how to judge the outcome of such tests, and how to proceed in further testing. Both these forces are social - and they are forms of teaching - in the sense we will now explicate. Both forces are the work of human mentors, teachers, social groups, and of environments that have been engineered by both human evolutionary forces and institutions and social practices (Tomasello, 2016). Due to the arbitrary and conventional nature of cultural reality, it is necessary that someone familiar with the codes, the languages, the correct use of the artifacts, is available to teach others how to use and interpret the signs and symbols, as well as how to form part of, and incorporate oneself in, human practices and groups.

From this viewpoint, the experiential base necessary for learning - edited and annotated experiences stored in LTM and used in mental simulations for future action and planning) is socio-mental. It is both inside the head and thoroughly structured outside the head by mentors, teachers, social groups, and designed environments. It is the product of learning and teaching as forces that cannot be clearly separated. In this sense, learning is a process located and distributed between the learner and those artifacts, mentors, people and environments participating in the learning experience (EstebanGuitart, 2016). However, despite the unity of the teaching and learning processes, they are different phenomena in the sense that they have different objectives and functions. In fact, as Vygotsky (1978) would say, the teaching process (educational change) precedes, prepares, facilitates and promotes the learning processes (evolutionary or psychological change). 
Teaching becomes the design of experiences that are good for learning and the social "gift" of the judgment/assessment systems learners need to make sense of experience, to evaluate the outcome of choices and actions, and to engage in testing hypotheses in the world. Like memory, and experience, teaching and learning become more about the future than the past. The fundamental goal of teaching becomes designing experiences and practices that allow learners to make good choices and judgments in the future based on good teaching and learning in the past. Teaching and learning become preparation for a future in a complex and often unpredictable world.

This sort of teaching process has been fundamental to our evolution as a species. Teaching - and not just genes - formed the human mind. This sort of teaching process is core, also, to the survival of many institutions in modern societies. And, importantly, it has proliferated massively - in perhaps new evolutionary terms - out of school in interest-driven affinity spaces on the internet (and often, too, in related real-world spaces) where people distribute teaching and learning in the service of an interest or passion across many different spaces, technologies, and diverse ways of teaching and learning. We are in a new age - maybe even "the" age - of teaching.

In this emerging view of teaching-learning as socio-mental, teachinglearning is not restricted to formal institutions. It never has been, of course, but today it is more than ever ubiquitous outside of school (Esteban-Guitart, Coll, \& Penuel, 2018). Teaching seen broadly constitutes a continuum from our human evolutionary heritage and ever-present human environmental design through various forms of teaching in social groups, cultures, and new virtual spaces to formal teaching in schools. This new view suggests that we cannot understand teaching and learning - nor train teachers for the modern world - if we ignore the full continuum of teaching as the basis of human socio-mentality and a human future.

\section{Distributed Teaching and Learning}

From an evolutionary and comparative perspective, it seems that our species is the only one that shares an experience simply for the sake of sharing it (Tomasello, 1999). That is, for the simple benefit of sharing the action and attention together. When a chimpanzee 'shows' its offspring that termites can 


\section{Esteban-Guitart \& Gee-Deep Teaching and Learning}

be retrieved and eaten using a stick, it does so for biological reasons, to get food. However, when a child shows its father a ball and says "Look, Dad!" the only benefit is that of sharing attention and the experience. In many cases, what is shared is, in fact, an affinity: a common interest bringing together people who might well be rather different from a social and cultural perspective. And the affinity spaces in which this takes place are, in most cases, informal.

We pointed out earlier that some sorts of out-of-school learning reflect deep learning principles better than many of today's schools do. These outof-school sites constitute what have been called "affinity spaces" (Gee, 2004, 2007, 2015, 2017; Gee \& Hayes, 2011). In our view, these affinity spaces comprise the geography in which the learning processes take place. By learning processes, we mean the itineraries or trajectories that lead people to participate in different 'ecological niches' (activities and practices with particular artifacts and people). The best affinity spaces for deep learning are "distributed teaching and learning spaces" (Gee \& Gee, 2018; Gee, 2017; Holmes, 2016). This means they do not locate teaching in one person or one location but across many people, tools, locations, and contextually-sensitive practices.

In an affinity space, a shared affinity for solving problems of a certain sort is a kind of glue that binds people - more or less tightly - together. A big affinity space is composed of a set of smaller interconnected spaces all of which "smell" of this glue, as people leave behind the "scent" of the glue in all these spaces as they act - often teaching and learning - in them with others. One example of an affinity space (= a space of many interconnected spaces) is a certain type of fan-fiction writing, as we will explain below. But the problem to be solved can be nearly anything, for example, various problems in media production, gaming, women's health, citizen science, activism, and so forth.

Affinity spaces are "attractors" to a particular identity, drawing in people who engage in certain activities to solve certain sorts of problems. There are many activity-based identities in the world - and they appear and disappear during the course of history. Take, for example, gardeners and gardening, to which a large number of affinity spaces are devoted. 
Activity-based identities - and their associated affinity spaces - are composed of many sub-types. They are homes of modern forms of everexpanding diversity. Gardeners can grow one type of plant or many; they can be fruit and vegetable gardeners or flower gardeners or both; they can do organic gardening or not; they can garden to create landscapes or to grow food; they can engage in community gardening or garden at home; they can be casual gardeners, high-tech gardeners, large-scale gardeners, or serious gardeners with small plots; they can be container gardeners, raised-bed gardeners, urban gardeners, indoor gardeners, or even butterfly gardeners (growing plants that will attract butterflies). These are only a few of the many different things gardeners can be.

Activity-based identities are identities that people identify with by free choice. It is important to note, though, that activity-based identities are not in a person. They are a reciprocal relationship between a person and a social group and its core defining activities. Such identities change in history as groups change their activities, norms, values, or standards. Some activitybased identities go out of existence and some new ones arise. Activity-based identities are ways for people to identify with something outside themselves, something that other people do and are.

Activity-based identities are the stuff of which affinity spaces are made. Affinity spaces are the spaces through which people move and act because they have an affinity for a given identity and how it plays out in the world. People who are merely interested in this identity can enter some of these spaces, but they must, for the most part, respect the people who have deep interest or true passion for the identity as the attractors to the space and the central (but not only) distributed leaders and teachers in it.

\section{Modern Affinity Spaces. The Example of Video Games}

Today it would be difficult to name a problem and associated identity that is not being discussed in one or more affinity spaces somewhere in the world. Such problems include things like media production, citizen science, political activism, women's health, fan-fiction writing, video games, specific diseases, and almost anything else you can name. In these affinity spaces 


\section{Esteban-Guitart \& Gee-Deep Teaching and Learning}

people act, teach, learn, and produce without regard to credentials, age, outside status, or degrees of expertise.

Now we want to discuss one specific area - namely video games - where we can see potential uses of affinity spaces for teaching and learning (Gee, \& Gee, 2018; Gee, 2007). Video games have become an area where we, as educators, have something to learn when it comes to organizing interest and passion. This is not a plea to use video games in school. It is a plea to use video games for thinking about and reflecting on how to improve teaching and learning, with or without games.

A video game is just a set of well-designed problems to solve. The design of the game teaches and mentors players to solve the problems, using good principles of teaching and learning. A game can be designed around any welldefined and challenging set of problems, e.g., designing civilizations (Civilization), fighting wars (Call of Duty), solving algebra equations (Dragon Box), building a family and community (The Sims), or cleaning a house when you are a four-inch tall house-cleaning robot (Chibi-Robo).

Gamers do not just play games. When they have a real interest or passion for a game or a type of game they often take their game-based learning into modern affinity spaces.

For many gamers, their gaming room at home is connected not only to the virtual spaces of the games themselves, but to other interest-driven internet sites where they discuss, learn, and teach about the games they play. For these gamers, their gaming rooms are also connected to other physical spaces, such as gaming rooms in friends' homes; LAN parties; stores where gamers gather; gamer conventions; gamer clubs; and, perhaps, too, places where they play non-digital table-top games.

This whole set of physical and virtual spaces that characterize the comings and goings of gamers is an affinity space composed of many other subspaces. These sorts of affinity spaces today are often "squishy". They are fluid and ever changing. They are hard to strictly demarcate. Spaces and subspaces come, go, and transform as the interest/passion that fuels them evolves and as technologies change.

Each gamer takes different looping itineraries through gamer affinity space. We could, if we like, map out for each person, at any period of time, what parts of the affinity space he or she inhabits and how. If we did this for 
a gamer named Mary, we could say we had drawn a map of Mary's (version of) gamer affinity space. This "Mary map" will change across time, but might well remain reasonably stable for periods of time.

So, imagine Mary is devoted to playing and designing for The Sims. We can take a certain period of time - a day, a week, a month, or many months - and map out all the spaces, physical and virtual, and all the routes among them, that Mary uses in pursuit of her interest or passion.

We could make the boundary lines on some spaces and routes on the map thicker than others, based on how much time Mary spends in that space or returns to that space. The thicker the lines, the more time she tends to spend there. We can also, if we like, color-code various spaces and routes based on the sorts of things Mary does in them.

This would be a map of Mary's Sims affinity space. The Sims affinity space is, of course, one relatively large part of the overall gamer affinity space. And we can draw a Mary map for this too if she plays other games as well. The sub-parts of Mary's Sims affinity space - whether they are small parts like her game room at home or larger parts like a gaming convention space (with many rooms) or a fan-based, interest-driven internet site devoted to The Sims (also with many virtual rooms) - are affinity spaces within Mary's overall Sims affinity space.

Now take the map we have made for Mary. It is, in some respects, unique to Mary. Certainly, her moment by moment pattern of movement and activity is unique. But, if we compare Mary's Sims affinity space to other people's Sims affinity spaces we will find more or less overlap with Mary's. The set of people who have a significant overlap with Mary's map constitute a squishy (not rigidly bounded or defined) group. We called this group "fellowtravelers". Fellow travelers vary with time and circumstances and some are together longer than others. It's fluid.

Mary interacts with (or, at least, has ample opportunity to interact with) these fellow travelers. However, anyone who has been in any one of the spaces in her larger Sims affinity space is in a yet larger and more amorphous group with Mary. These are people we can call "affines". Just because Mary sees some of these people rarely, any given interaction might be significant and, so, nobody can be discounted. Frequency of contact is not the only significant variable here. 


\section{Esteban-Guitart \& Gee - Deep Teaching and Learning}

Mary, of course, can traverse different - even many different - affinity spaces and some of these might have close relationships to each other. For example, Mary may journey in The Sims gaming affinity space and in a Photoshop affinity space. These two affinity spaces might be closely related for Mary because she both plays The Sims and Photoshops images from The Sims for graphic fan-fiction. She may, then, also be in a The Sims fan-fiction affinity space, and maybe, too, a more general fan-fiction affinity space. In two or more of these affinity spaces Mary may have some of the same fellow travelers.

It might also be that one specific interest-driven website - for example TSR Workshop (http://www.thesimsresource.com/workshop/) - is so central to Mary's Sims endeavors that we can focus on and study it alone as the heart and soul of her endeavors in affinity space, though still tracing where Mary comes from to get there and where she sometimes goes from there (or is led to). We can call such sites "home bases". People could have several home bases, or none, and some can be physical and others virtual. In Figure 3, we sketch out some of the spaces a person might inhabit and travel among in the much larger Sims affinity space.

In Figure 3, shapes with dark borders are virtual, those without are physical. Triangles are home-bases. The arrow means that Photoshop is part of a bigger Photoshop affinity space as well.

In each space, there are teachers and learners. In some spaces people teach and in others they learn and in some they do both. In each space and across them all, there exist many different tools, resources, and teaching practices that people can use to customize their learning experiences. For example, consider this short list below of the many spaces available to gamers who play the very popular multi-player game DOTA 2. This list comes from a doctoral dissertation by Holmes (2016). Note the blend of people, activities, tools, resources, and production (not just consumption) characteristic of modern affinity spaces. Here there are many human and non-human (tools, resources, and practices) teachers and, further, teaching and learning are flexible roles. Some people in any affinity space become "masters" due to achieving the high standards such spaces tend to create and "police" bottom up. These people become the main attractors, central teachers, and norm setters of the affinity space or significant sub-parts of it. In most cases, the status of "master" is 
open to anyone who wants to put in the time and effort, though there is not obligation for people do so in order to use the affinity space for their own goals and desires.

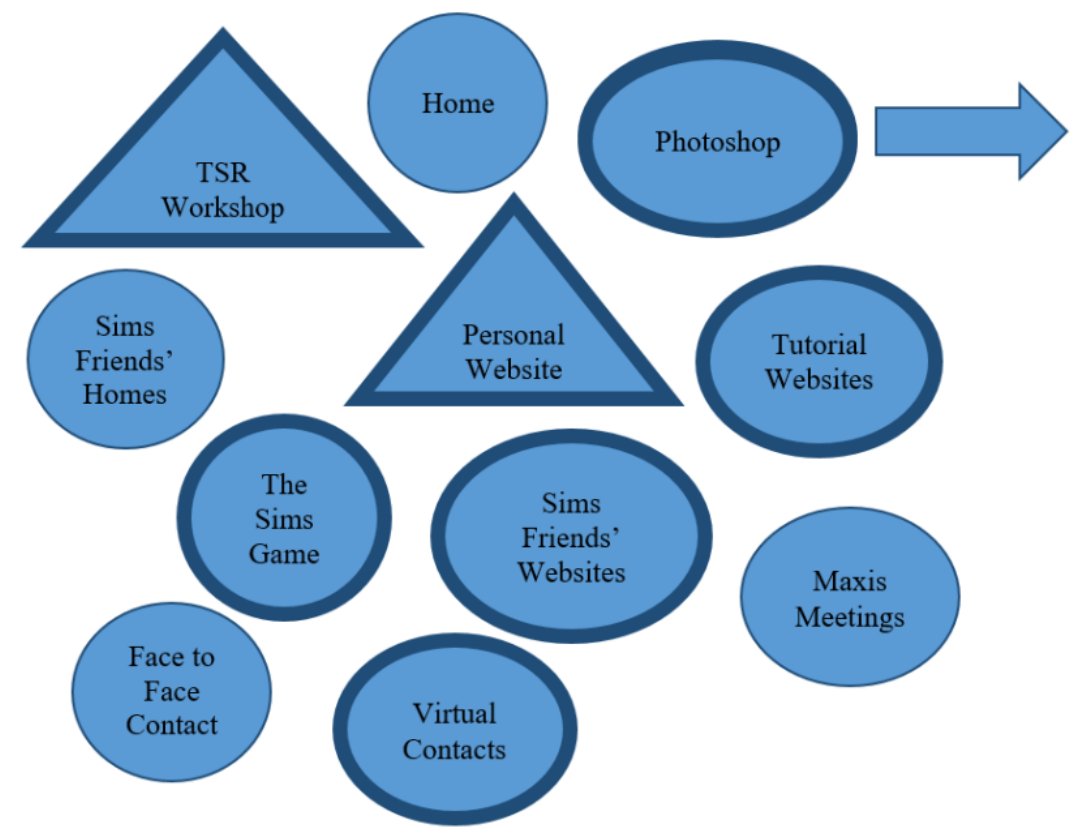

Figure 3. Some of the spaces in The Sims affinity space. 


\section{Conclusion: The Challenge of Formal Education}

Many schools today, across the world - engaged with the traditional formal style of Western schooling - bear very little resemblance to distributed teaching and learning, interest-and-passion-driven, affinity spaces. They do not represent deep teaching and deep learning of the type going on out of school. So, the question often arises: What can schools do to engage with this new sort of deep teaching and learning. An initial answer is: open the door; connect to other physical and virtual spaces; send the learners on journeys across multiple spaces; make the classroom and the school control zero for designing, aggregating, and resourcing customized journeys for all learners with the goal that they eventually learn to map out their own journeys as selfdirected learners (which is to say to become their own master teachers).

If they wish to survive in today's teaching and learning scenarios defined in this article as modern affinity spaces - the main challenge for schools involves a radical transformation of their parameters or coordinates. The notion of learning that we have outlined here entails doing away with the idea of learning taking place in one space, at one time and in one way. We are witnessing a broadening of the notion of learning towards more inclusive perspectives that recognize the located and distributed nature of teaching and learning that now, more than ever before, is operating in our societies. In our view, this means that schools must reinvent themselves in order to contribute to the generation of deep learning among their students. The reality is that, in themselves, affinity spaces are not regulatory centers of teaching and learning; they do not produce critical reflections on the status and nature of the participants' learning. The school can, in this sense, become the hub that interconnects the different contexts and learning scenarios (i.e., the different affinity spaces of learners) by providing guidance, orientation and enrichment of their particular learning trajectories. To do so, schools need to promote meta-knowledge about the trajectories, experiences and these formal and informal learning spaces. That is, they need to promote critical analysis, reflection, discussion and understanding of the various artifacts, spaces and practices in which the learner participates (for example, knowing how the Internet and its platforms such as Google or Whatsapp actually work). 
Table 1

Several sub-spaces in the larger DOTA 2 Affinity Space.

\begin{tabular}{l|l}
\hline In-game tutorial & $\begin{array}{l}\text { Covers everything from basic camera and character } \\
\text { movement to complex, multi-player battles. }\end{array}$ \\
\hline $\begin{array}{l}\text { In-game knowledge } \\
\text { library }\end{array}$ & $\begin{array}{l}\text { Players can look up information about every aspect } \\
\text { of the game. }\end{array}$ \\
\hline "Coach" mode & $\begin{array}{l}\text { Players can get a coach who will come into their } \\
\text { game and help them play the game in real time. }\end{array}$ \\
\hline $\begin{array}{l}\text { Community character } \\
\text { builds and guides }\end{array}$ & $\begin{array}{l}\text { Players "spec" heroes with different equipment and } \\
\text { abilities, often explicate their choices, and share them } \\
\text { with other players. }\end{array}$ \\
\hline mode & $\begin{array}{l}\text { Players use their own game client to watch the } \\
\text { games. They have features such as the ability to } \\
\text { change their screen to an individual player (including } \\
\text { their interface), to a free-roaming camera, and even } \\
\text { to a "directed" camera that is controlled by a } \\
\text { commentator. }\end{array}$ \\
\hline Twitch streams & $\begin{array}{l}\text { Twitch is a major site for live game streams. Like the } \\
\text { in-game streams, these spaces serve as teaching } \\
\text { through modeling, commentary, and player } \\
\text { communication. Popular streamers often drive } \\
\text { community practices by using particular builds or } \\
\text { strategies or other practices. }\end{array}$ \\
\hline & $\begin{array}{l}\text { Dotafire.com is a forum site where players can post } \\
\text { hero builds and discuss strategies (among other } \\
\text { things). Many members engage in a practice known } \\
\text { as "theorycrafting" where they formulate often } \\
\text { complex models of how various abilities relate and } \\
\text { work to maximize performance. }\end{array}$ \\
\hline
\end{tabular}

Such an objective would distance the school from any suggestion of indoctrination; instead, the school would become an intermediate space connecting the various learning experiences of the people. For this to work, 


\section{Esteban-Guitart \& Gee-Deep Teaching and Learning}

it is necessary to connect and integrate the elements that characterize deep learning: knowing, doing, evaluating and being, through the design and mentoring of deep learning, where there is a real (virtual and/or physical) action to be performed (a problem to solve), where learners care about the outcome of the action, and where they are helped to manage their attentional resources. What is done inside and outside the school needs to be connected. Literacy activities can, for example, be brought together within the larger ecologies of activities of all kinds which give any specific literacy activity or skill its meaning, its power, and its potential for good or bad effects in the world.

Affinity spaces, in themselves, are morally neutral. They can, at the same time, be vehicles of both civil expression and terrorist dogma. Making good use of them, learning to convert the new languages and tools into learning devices, being aware of the opportunities they bring, as well as their limitations, seems to us to be not just a noble aim, but also a necessity for schools in the $21_{\text {st }}$ century.

\section{References}

Barron, B., \& Bell, P. (2015). Learning environments in and out of school. In L. Corno, \& E. Anderman (Eds.), Handbook of educational psychology (3rd ed., pp. 323-336). New York, NY: Routledge. Bransford, J. D., Brown, A. L., \& Cocking, R. R. (2000). How people learn: Brain, mind, experience, and school. Washington, DC: National Academy Press.

Ausubel, D. (1963). The psychology of meaningful verbal learning. New York, NY: Grune \& Stratton.

Buonomano, D. (2011). Brain bugs. How the brain's flaws shape our lives. New York, NY: W. W. Norton \& Company.

Delgado, M.R. (2012). A brain bug's life. Trends in Neurosciences, 35(4), 209-210. doi: 10.1016/j.tins.2012.02.002

Elman, J. L. (1993). Learning and development in neural networks: the importance of starting small. Cognition, 48(1), 71-99. doi:

10.1016/0010-0277(93)90058-4 
Esteban-Guitart, M. (2016). Funds of identity. Connecting meaningful learning experiences in and out of school. New York, NY:

Cambridge University Press.

Esteban-Guitart, M., Coll, C., \& Penuel, W. (2018). Learning across settings and time in the Digital Age. Digital Education Review, 33, 116. Retrieved from http://revistes.ub.edu/index.php/der/article/view/22351

Gee, J. P. (2004). Situated learning and language: A critique of traditional schooling. London, UK: Routledge.

Gee, J. P. (2007). What video games have to teach us about learning and literacy (2nd ed.). New York, NY: Palgrave/Macmillan.

Gee, J. P. (2015). Literacy and education. New York, NY: Routledge.

Gee, J. P. (2017). Teaching, Learning, Literacy in our High-Risk High-Tech World. A Framework for Becoming Human. New York, NY:

Teachers College Press.

Gee, J. P., \& Hayes, E. R. (2011). Language and learning in the digital age. London, UK: Routledge.

Gee, J. P. \& Esteban-Guitart, M. (2019). Designing for deep learning in the context of digital and social media. Comunicar, 58, 9-17. doi:

10.3916/C58-2019-01

Gee, E. R., \& Gee, J. P. (2018). Games as distributed teaching and learning systems. Teachers College Record, 119(12), 1-22.

Holmes, J. (2016). Video games, informal teaching, and the rhetoric of design (unpublished doctoral dissertation). Arizona State University, Tempe.

Ito, M., Gutiérrez, K. Livingstone, S., Penuel, B., et al. (2013). Connected Learning: An Agenda for Research and Design. Irvine, CA: Digital Media and Learning Research Hub.

Jenkins, H. (2009). Confronting the challenges of participatory culture. Media education for the 21st century. Cambridge, MA: The MIT Press.

Jenkins, H. Ito, M., \& Boyd, D. (2016). Participatory Culture in a Networked Era. A Conversation on Youth, Learning, Commerce and Politics. Cambridge, MA: Polity Press. 


\section{Esteban-Guitart \& Gee-Deep Teaching and Learning}

Klein, S. B., Robertson, T: E., \& Delton, A. W. (2010). Facing the future: Memory as an evolved system for planning future acts. Memory and Cognition, 38(1), 13-22. doi: 10.3758/MC.38.1.13

Kolb, D. A. (2015). Experiential Learning. Experience as the Source of Learning and Development. New Jersey: Pearson Education.

Lázaro, L., \& Esteban-Guitart, M. (2014). Acts of shared intentionality. In search of uniquely human thinking. Ethos, 42(4), 10-13. doi: 10.1111/etho. 12066

Lee, C. D. (2017). Integrating research on how people learn and learning across settings as a window of opportunity to address inequality in educational processes and outcomes. Review of Research in Education, 41(1), 88-111. doi: 10.3102/0091732X16689046

Lucas, G. M., Gratch, J., King, A., \& Morency, L. P. (2014). It's only a computer. Computers in Human Behavior, 37, 94-100. doi: 10.1016/j.chb.2014.04.043

Marblestone, A., Wayne, G., \& Kording, K. (2016). Toward an integration of Deep learning and neuroscience. Frontiers in Computational Neuroscience, 10, 94-115. doi: 10.3389/fncom.2016.00094

Packer, M. J., \& Cole, M. (2019). Evolution and ontogenesis: The deontic niche of human development. Human Development, 62, 175-211. doi: 10.1159/000500172

Reber, A. S. (1989). Implicit learning and tacit knowledge. Journal of Experimental Psychology: General, 118(3), 219-235. doi: 10.1037/0096-3445.118.3.219

Sekeres, M. J., Wincour, G., \& Moscovitch, M. (2018). The hippocampus and related necortical structures in memory transformation.

Neuroscience Letters, 680, 39-53. doi: 10.1016/j.neulet.2018.05.006

Skinner, B. F. (1954). The science of learning and the art of teaching. Harvard Educational Review, 24(2), 86-97.

Subero, D., Llopart, M., Siqués, C., \& Esteban-Guitart, M. (2018). The mediation of teaching and learning process through identity artefacts. A Vygotskian perspective. Oxford Review of Education, 44(2), 156170. doi: 10.1080/03054985.2017.1352501 
Tallis, R., \& Aleksander, I. (2008). Computer models of the mind are invalid. Journal of Information Technology, 23, 55-62. doi:

10.1057/palgrave.jit.2000128

Tomasello, M. (1999). The cultural origins of human cognition.

Cambridge, MA: Harvard University Press.

Tomasello, M. (2014). A natural history of human thinking. Cambridge,

MA: Harvard University Press

Tomasello, M. (2016). Cultural learning redux. Child Development, 87(3), 643-653. doi: 10.1111/cdev.12499

Tomasello, M. (2019). Becoming Human: A Theory of Ontogeny.

Cambridge, Massachusetts: Harvard University Press.

Vadeboncoeur, J. A., Kady-Rachid, H., \& Moghtader, B. (2014). Learning in and across contexts: Reimagining education. National Society for the Study of Education, 113(2), 339-358. Retrieved from

https://www.researchgate.net/publication/274834602_Learning_in_a nd_across_contexts_Reimagining_Education

Vygotsky, L. S. (1978). Mind in society. The development of higher

psychological processes. Cambridge, MA: Harvard University Press.

Wertsch, J. V. (1997). Mind as action. Oxford, UK: Oxford University Press.

\section{Moisés Esteban-Guitart Universitat de Girona}

Contact Address: Facultat d'Educació i Psicologia, Institut de Recerca Educativa, Campus Barri Bell, Plaça Sant Domènec, 9, 17004, Girona, Spain.

e-mail: moises.esteban@udg.edu 